\title{
Re-existências decoloniais - a potência dos clipes Mandume, Boa Esperança e Eminência Parda
}

\author{
Decolonial re-existences - the strength of the music videos Mandume, \\ Boa Esperança and Eminência Parda
}

\section{DENISE FIGUEIREDO BARROS}

\section{DO PRADO}

Professora do Programa de Pós-

Graduação em Comunicação e do Departamento de Jornalismo da Universidade Federal de Ouro Preto. Doutura pela Universidade Federal de Minas Gerais e PósDoutorado pela Universidade Federal do Rio de Janeiro. Líder do Grupo de Pesquisa em Mídia e Interações Sociais - Giro. https://orcid.org/0000-00020547-9896

denisefbp@gmail.com

\section{RESUMO}

Este artigo discute como os clipes Mandume, Boa Esperança e Eminência Parda, do rapper Emicida, realizam um retorno à ferida colonial e apontam opacidades históricas, opressões e exclusões daí derivadas, como forma de conduzir a uma releitura afetiva e resistente do/no tempo e instigar ações estéticas de re-existência. Para isso, realizamos uma análise audioverbovisual dos clipes procurando observar a construção desse discurso a partir de três categorias analíticas: retorno memorialístico, corporalidade desumanizada e vida livre da violência e da morte.

\section{Palavras-chave: Ferida Colonial;}

Clipes; Re-existência estética.

\section{ABSTRACT}

This article discusses how the music videos Mandume, Boa Esperança and Eminência Parda produced by the rapper Emicida, access the colonial wound and point out historical opacities, oppressions and exclusions derived therefrom, as a way to lead to an affective and resistant rereading of / in the time and to instigate aesthetic actions of re-existence. For this, we performed an audiovisual analysis of the music videos, seeking to observe the construction of this discourse from three analytical categories: memorialistic return, dehumanized corporeality and a life free from violence and death.

Keywords: Colonial Wound; Music videos; Aesthetic re-existence. 


\section{INTRODUÇÃO}

Que o rap se constitui como um campo para diálogo e construção de novas posições de sujeito não é novidade: é um gênero musical que nasceu e se fortaleceu no seio de uma disputa pela reconstrução do lugar social dos seus artistas e públicos, reivindicando outras maneiras de ver e viver o mundo.

Bhabha (1998) nos destacava a importância social da diversidade de relatos, especificamente das histórias reprimidas das minorias. Mais do que expor perspectivas constituídas a partir de diferentes experiências sociais, essas narrativas - há muito silenciadas - evidenciam a existência de uma comunidade intersubjetiva que partilha sentimentos e modos de vida, transcendendo tempos e espaços. Com Evaristo (2007), a partir da noção de escrevivências, compreendemos a articulação narrativa como um saber e um poder: o exercício de narrar-se a si mesmo, constituir e conformar um relato da própria experiência, é capaz de modificar e transformar o sujeito e a forma como ele produz - reflexivamente - seu lugar no discurso. Ao compor uma narrativa, dá-se tonalidade ao vivido por meio de uma leitura em retrospecto, articuladora, dos próprios sentidos do ser. Camargos (2015) nos auxilia a pensar essa dimensão narrativa do rap a partir da sua vinculação ao cotidiano, ao explicar que, "no caso do rap, o que chama a atenção é o fato de as transformações que conhecemos como históricas e/ou com certo distanciamento, serem apresentadas, com bastante ênfase como experimentadas na própria carne (...)" (CAMARGOS, 2015, p. 130-131).

Por certo, o relato da experiência no rap não é inaugural, uma vez que as narrativas centradas no cotidiano são constitutivas desse gênero musical (TEPPERMAN, 2014). No entanto, não se pode negar que elas ganham outros contornos ao incorporar, nos últimos anos, com a chamada "nova geração" - na qual despontam, além de Emicida, Crioulo, Djonga, Linn da Quebrada, Drik Barbosa, entre outros e outras - uma reflexão sócio-histórica sobre as experiências temporais de longa duração. Tal abordagem colabora para o tratamento de temas como o passado colonial e a escravização - enquanto ferida colonial (MIGNOLO, 2005) - e sua afetação no tempo presente. Diante disso, nesse artigo, nos dedicamos a problematizar essa constituição do rap, na qual se articula a dimensão histórica da própria experiência para, por meio de um gesto artístico e cultural, realizar-se uma (re)escritura memorialística do passado.

Para isso, analisamos as dimensões discursivas audioverbovisuais dos clipes Boa Esperança (2015) ${ }^{[1]}$, Mandume ${ }^{[2]}$ (2016) e Eminência Parda ${ }^{[3]}(2019$,$) do rapper Emicida, discutindo como, ao$ acionar a ferida colonial, eles propõem uma releitura afetiva e resistente $d o / n o$ tempo perfazendo uma trajetória que aponta as opacidades históricas, as opressões e exclusões, bem como suas permanências, no cotidiano da população negra do Brasil. 
Destacamos que a seleção desses três clipes não é aleatória. Desde o início de sua carreira, Emicida despontou como um nome forte no rap nacional. Para além dos processos de celebritização em franco desenvolvimento na sua trajetória midiática (PRADO, 2020), ele aparece como uma fala lúcida para conduzir o debate e a crítica sobre as violências sofridas pela população negra e a necessidade de valorização da cultura afrodiaspórica no cenário nacional. O tema do racismo se faz presente em suas múltiplas obras - nos palcos, nas passarelas, nos livros - mas, no caso das três produções selecionadas, temos uma particularidade. A nosso ver, os clipes operam como um "tríptico"; colocados lado a lado, iluminam, revelam e sintetizam faces complexas e integradas de um mesmo tema: o racismo enquanto herança colonial que atravessa a vida social. Diante disso, conforme veremos a seguir, problematizamos como os clipes propõem um gesto de re-existência e crítica estética do racismo por meio do acionamento da ferida colonial.

\section{A FERIDA COLONIAL: DESVELANDO AS OPACIDADES DO PASSADO}

Falar em ferida colonial, mais do que situar um momento de dor ou lamento como algo debilitante e que precisa ser superado, incita à identificação de uma marca histórica que precisa ser conhecida, narrada e reconstruída para transformar a relação com o mundo social. Ou seja, ao trazer à tona o passado colonial e revisitar as feridas compartilhadas por meio de outras narrativas e experiências, instaura-se uma abertura para o questionamento da colonialidade no tempo presente. Nas palavras de Mignolo (2005), "las explosiones provenientes de la conciencia teórica, política y ética de la herida colonial despiertan la imaginación y permiten la construcción de otro mundo, un mundo en el cual muchos mundos son posibles" ${ }^{[4]}$ (MIGNOLO, 2005, p. 175176 , grifos nossos).

A ferida colonial é uma marca histórica constituinte da estrutura social e, no entanto, muitas vezes é negligenciada ou esquecida, vista como algo pertencente a um passado não problemático (nem problematizável). Ao olhar para ela, encara-se as memórias dela derivadas, torna-se possível narrar e reivindicar um outro lugar no tempo histórico e encampar gestos de crítica e resistência. Compreender essa ferida é, então, importante enquanto memória, pois quando se resiste ao seu esquecimento e apagamento, entende-se como o passado se torna manifesto no cotidiano pelas múltiplas colonialidades que cercam a vida social. Por isso, conforme Mignolo (2007), o retorno à ferida colonial, é potente: tal gesto conduz ao entendimento da profundidade da experiência da colonialidade no mundo social, permitindo a constituição de uma abertura 
à liberdade de pensamento e a outras formas de vida, estimulando, assim, um processo de transformação social.

Embora não seja o objetivo deste artigo aprofundar no complexo debate sobre as formas de constituição da colonialidade - o que pode ser largamente e melhor compreendido pelas contribuições de diversos autores, em especial, de Mignolo (2008) e Quijano (2005) - destacamos três eixos principais dessa experiência, que acabam se alastrando e reverberando em aspectos mais amplos da vida social e institucional na América Latina: a colonialidade do poder, do saber e do ser.

A colonialidade do poder se refere à força que os sistemas e instituições se apropriam da autoridade sobre o mundo social e material, ganhando centralidade na exploração dos recursos e da mão de obra, dando sustentação ao desenvolvimento e expansão do capitalismo até contemporaneamente. A colonialidade do saber alcança a dominação e a centralização das formas de conhecimento, negando e/ou relegando a segundo plano outras epistemes. Já a colonialidade do ser - à qual nos dedicamos mais diretamente nesse artigo - incide na subjetividade dos povos, na sua linguagem e expressividade, atingindo a dimensão ética e estética que ordena e orienta as relações sociais. A colonialidade do ser se fundamenta na obliteração das diferenças a partir de um discurso de universalidade do humano centrada no sujeito imperial (europeu, moderno, branco, heterossexual) em face de um sujeito subalternizado, racializado e generificado (MIGNOLO, 2005).

Maldonado-Torres (2007) explica que a colonialidade do ser se faz presente, para além da experiência vivida da colonização, nos seus desdobramentos de longo prazo, atravessando a linguagem, o imaginário, as subjetividades e os valores. Mais do que uma abordagem subjetivista, essa perspectiva mostra como as dinâmicas sócio-históricas afetam as relações sociais, das mais profundas às mais corriqueiras, encontrando eco na vida social. Por esse viés, entende-se que a colonialidade possui uma presença prática, afetando a estrutura social, as instituições e os campos sociais, assim como a vida cotidiana e as formas de compreender e organizar as experiências, incidindo nas maneiras de ser e estar no mundo. Com isso, sua problematização se torna transformadora ao permitir o apontamento de fraturas e dissonâncias, questionar a noção de passado como algo superado, encerrado no tempo, fazendo emergir uma retomada crítica da história.

Mais precisamente, a colonialidade do ser se fundamenta na negação da humanidade do sujeito colonizado e racializado pelo sujeito imperial: ou seja, ao colocar em questão a dimensão humana dos sujeitos colonizados, impõem-se a eles uma marcação de inferioridade (LUGONES, 2014) ${ }^{[5]}$. Tal forma de constituição de lugar de sujeito se ancora em um dualismo necessariamente depreciativo, cuja consequência é a hierarquização desumanizadora pela "linha da cor". Esse mundo - material e simbólico, emergente pela colonialidade - se estrutura por meio de uma 
relação perversa, na qual a violência, a morte e o sofrimento dos sujeitos colonizados não são problematizáveis, fazendo da existência uma experiência "infernal", traduzida pela naturalização da violência corporal e letal. A consequência mais nefasta dessa relação é que a experiência da morte e da violência seja algo que ronda a vida dos sujeitos, que lhes envolve de tal forma que se torna constitutivo de sua experiência no mundo: "la anticipación de la muerte no es tanto un factor individualizador como un rasgo constitutivo de su realidad"[6] (MALDONADO-TORRES, 2007, p. 143$)^{[7]}$.

Diante das brutalidades impostas pelas lógicas da colonialidade, o pensamento decolonial propõe o questionamento dessa relação estabelecida que naturaliza e morte e a violência e a desumanização dos sujeitos - calcada na racialização e generificação - como estruturas imutáveis no social.

Realizar esse questionamento exige um retorno memorialístico ao passado, no qual os sujeitos demandam um lugar na reescritura histórica das experiências constitutivas do tempo. Esse retorno memorialístico, mais do que uma recuperação histórica ou "redescoberta" de fatos, personagens e narrativas ocultadas permite dois gestos epistemológicos fundamentais para estruturar uma ruptura e uma ação estética de intervenção no presente: (1) a constituição coletiva e ampliada de outras narrativas, nas quais se entrelaçam diversas experiências e sujeitos; e (2) uma retomada do tempo histórico, encarado como constitutivo do presente e passível de desnaturalização, a fim de questionar o lugar constituído para os sujeitos. Ou seja, mais do que mero revisionismo, exige-se uma atualização transformadora do tempo, cujas consequências devem conduzir a uma remodelação do social, colocando em xeque as lógicas impostas à corporalidade dos sujeitos e à angústia da violência e da morte como parte do cotidiano.

A ruptura com a corporalidade desumanizadora tenta restaurar a dignidade e integridade do corpo como campo expressivo e constitutivo da experiência do ser; destituí-lo de marcas que o associam à hipersexualização dos corpos negros (seja pelo discurso falocêntrico, seja pelas fantasias de violação e posse do corpo do/a outro/a) (LUGONES, 2014), à exploração do trabalho como recurso - destituindo o outro de cultura, inteligência, humanidade e dignidade legitimando opressões econômicas, sociais e emocionais (TATE, 2019), bem como à depreciação estética das múltiplas corporalidades.

Ao exigir-se o reconhecimento do corpo e da experiência, do lugar de sujeito histórico, reivindica-se o direito à vida livre da violência e da morte, de se viver sem a ansiedade gerada pela violência, pelo assombro da morte precoce. Afinal, "lo que es invisible sobre la persona de color es su propria humanidad. $Y$ es sobre la negación de la misma que el grito/llanto ${ }^{[8]}$ intenta llamar la atención. La invisibilidad y la deshumanización son las expresiones primarias de la colonialidad del ser"[9] (MALDONADO-TORRES, 2007, p. 150). Por isso, a urgência da questão 
decolonial vigora nesse grito pelo reconhecimento da humanidade e da dignidade de si - que, nas palavras finais de Boa Esperança, se traduzem nas demandas emergentes do motim dos/ as empregados/as domésticos/as, no qual se exige respeito, dignidade e melhores condições de trabalho. Tal grito emerge de diversas maneiras, inclusive ao narrar as histórias, há muito ocultadas, que incomodam "os sonos injustos" da Casa Grande (EVARISTO, 2017) ${ }^{[10]}$. O retorno memorialístico e o reconhecimento da dignidade e da vida envolvem, também - para além de outras maneiras de se habitar o tempo e o espaço social - reinventar formas de narrar o passado, construí-lo e criticá-lo esteticamente, elaborando novas formas de expressão e presença cultural.

Tlostanova (2014) defende que a ruptura com a estética normativa ocidental é crucial para a emergência de novas experiências e sujeitos no campo da arte. Na sua perspectiva, o surgimento de uma estética decolonial - que, nos parece, é também promovida pelo rap - permite exercer uma remodelação subjetiva do lugar dos sujeitos no mundo, na qual se "[...] Trata de curar una mente y alma colonizadoras, libertando a la persona de complexos de inferioridad coloniales, y permitiéndole sentir que ella también es un ser humano con dignidad, que también es valiosa como es"[11] (p. 88).

Uma das formas de atender a essa reivindicação é apontada por Albán Achinte (2012), para quem a re-existência - um gesto político-estético de crítica e proposição de novas figurações dos sujeitos no campo da arte - se desdobra em múltiplas possibilidades de ações e práticas capazes de desarranjar os lugares instituídos de opressão, opacidade e silenciamento.

\footnotetext{
Seguramente lo que llamo de estéticas de la re-existencia no sean otra cosa que el acto político de vivir procurando, sin negociación alguna, alcanzar la dignidad y desestructurar las formas de poder y dominación que, desde lo material hasta lo simbólico, se construyen y circulan en esta época de un capitalismo desbocado y criminal. Tal vez las estéticas de re-existencia sean el susurro de prácticas decoloniales que avizoran formas otras de "buen vivir" "[12] (ALBÁN ACHINTE, 2012, p. 293).
}

A re-existência estética é uma ação a partir da qual se propõe formas alternativas de se fazer presente, de ser e estar no social, reposicionando e remodelando as relações intersubjetivas com a intenção de desnaturalizar formas de opressão legitimadas e consolidadas no quadro social. Enquanto gesto decolonial, ela se constitui em dois eixos: na diversidade estética, pois ao confrontar os padrões narrativos e as imagens desumanizadoras, faz-se emergir outras representações no quadro social; e no descentramento, quer dizer, na promoção de narrativas disruptivas, que contrariam as formas instituídas de posicionar e situar as relações entre sujeitos. Essa ação estética engloba então a desestruturação e crítica das formas coloniais de dominação com o objetivo de, ao se contrapor a elas, abrir o campo para a intervenção dos sujeitos, viabilizando a diversificação e a pluralização dos modos de ser e estar no mundo. Com essa abordagem, realizamos nossa análise. 


\section{MANDUME, BOA ESPERANÇA E EMINÊNCIA PARDA - CARACTERIZAÇÃO DESCRITIVO-ANALÍTICA}

O entremeado de sons e imagens formado pelos clipes Mandume, Boa Esperança e Eminência Parda constitui um tecido sonoro e imagético, no qual sentidos emergem propondo uma experiência multissensorial da canção (SOARES, 2014), acionam elementos do passado sóciohistórico brasileiro e denunciam sua presença no cotidiano contemporâneo. Tais clipes realizam um retorno ao passado como forma de promover reescrituras do nosso tempo, denunciando, assim, a ferida colonial que nos constitui e apontando as necessidades de resistência e de luta pela transformação social.

Os clipes derivam de parcerias de Emicida com diversos artistas - Drik Barbosa, Papillon, Rico Dalasam, Rael, Dona Onete, entre outras e outros - evidenciando o caráter coletivo das obras. Essa noção de coletividade está associada ao próprio discurso engendrado nas canções, nas quais o "nós", enquanto pronome inclusivo, instaura uma noção de comunidade de partilha - como ocorre em "Há quanto tempo nóiz se fode e tem que rir depois" (grifos nossos), em Boa Esperança. Neles, é explícita a intenção vinculante dos artistas: na interação entre eles, constituída com fins poéticos e estéticos, há o estabelecimento de um laço profundo com seus públicos, no qual o diálogo e a identificação convocam para uma adesão resistente e cooperativa diante das opressões racistas.

As figurações do racismo são centrais e aparecem sonora e visualmente não somente como experiência vinculante dos sujeitos e como algo a ser combatido, como também enquanto algo forjado no período colonial e ainda presente na vida cotidiana. Nas narrativas constituídas pelos clipes, demanda-se e realiza-se um retorno memorialístico ao passado como forma de promover reescrituras do nosso tempo para melhor compreendê-lo, a partir do acionamento da ferida colonial e das violências (simbólicas e materiais) constituídas e naturalizadas nesse período.

Essa necessidade de reescritura memorialística por um viés crítico e transformador já se anuncia no próprio título das canções: Mandume, rei do povo Caunhama (região do sul da Angola e norte da Namíbia), no início do século XX, ofereceu grande resistência às investidas alemãs e portuguesas durante a colonização africana; Boa Esperança era um nome recorrentemente atribuído a navios negreiros que - irônica e lamentavelmente - faziam a escravização soar como algo positivo, já anunciando as opacidades históricas que vinham sendo constituídas; e Eminência Parda é uma expressão usada nos círculos políticos que indica "aquele que influencia e direciona o governante, que sustenta o poder", ou seja, há um poder que reside oculto e precisa, enfim, exibir-se e elevar-se.

Boa Esperança (2015) mostra os mais diversos tipos de violência (sexual, corporal, religiosa...) impostos à população negra e sua vinculação com o passado colonial como momento fundacional da 
naturalização desses ataques. Ao trazer para o cerne da canção e das imagens a atualidade do passado, evidencia-se a presença das violências forjadas pela naturalização do racismo e da opressão social. Para sustentar essa crítica, o clipe recupera a afetação do passado colonial pela representação de trabalhadores negros sendo humilhados e assediados no trabalho doméstico em uma mansão (figurativa e imaginariamente representando a Casa Grande). Em meio às agressões, ocorre uma revolta, na sua potência transformadora, capaz de impor resistência e oposição aos dominantes. Ela se desdobra e sinaliza, ao final da produção, como uma ação que reverbera e se alastra nacionalmente, mostrando que, ainda que liminarmente contida pelos discursos apaziguadores dos telejornais, a revolta é "bomba relógio prestes a estourar" (Boa Esperança).

Já Mandume é uma produção que trata da representatividade conquistada pela ação dos sujeitos ao demandarem um "direito corporal à presença". Nela, escancara-se a branquitude das representações midiáticas e se denuncia o tom apaziguador que lhes cobra humildade (facilmente substituída pela subserviência), negando-Ihes o respeito a sua corporalidade. O corpo negro aparece em sua potência política, exigindo que não seja mais violentado pela brutalidade e pela sexualização, para dar lugar a uma forma de presença forte e respeitada. Esse tom reivindicativo já se anuncia nos primeiros versos quando a voz aveludada e algo de calma de Emicida parece descompassada com a dureza das palavras e do não-dito ao final dos versos: "Eles querem que alguém/Que vem de onde nóiz vem/Seja mais humilde, baixa a cabeça/Nunca revide, finge que esqueceu a coisa toda/Eu quero é que eles se... [som de apito suprimindo a palavra foda]".

Adiante, fechando o refrão, a voz de uma criança repete: "nunca deu nada pra nóiz, caráio/ nunca fez nada pra nóiz, caráio". Aí também se estabelece uma paradoxal correlação entre a fala infantil e a crueza da frase. Entretanto, para além disso, destaca-se a repetição algo descontínua, difásica, desta frase, replicando, melodicamente, o "engasgo", a mágoa presente ao fundo da composição. Essa descontinuidade sonora só se dilui e se converte em fluxo ao adentrar no flow das rimas que, mais do que ser um marcador das lógicas do rap, mostra que só ao enunciar o tema do racismo e da representatividade é que se recupera a fala sem travas, sem quebras, assumindo um ritmo nascente da potência do discurso.

A produção mais recente, Eminência Parda, centra-se na problematização das representações sociais, das imagens depreciativas associadas às pessoas negras e como a naturalização dessas representações impõe uma violência simbólica (que se desdobra em múltiplas formas estruturais e materiais). Se o tom da canção demanda um lugar de força e resistência para remodelar o quadro social - "Escapei da morte, agora sei pra onde eu vou / Sei que não foi sorte" (Eminência Parda) - a introdução do clipe e as imagens narram a história de uma família negra que vai a um restaurante francês comemorar as conquistas acadêmicas da filha. Durante o jantar comemorativo, o olhar constituído pelas pessoas brancas e ricas que estão ao redor impinge 
imagens de violência, crime, sexualização, exploração e morte. Nem mesmo a presença luminosa contrastante com as representações sociais arraigadas é forte o suficiente para fazer mover o racismo e o ódio social presente nos olhares que perfazem o entorno.

Ao longo dos três clipes são convocados três eixos que sustentam a emergência de um espírito transformador e re-existente: o retorno memorialístico para tensionar e remodelar o passado colonial, a crítica à corporalidade desumanizada e a defesa de uma vida livre da violência e da morte.

\section{a. Retorno memorialístico}

O retorno memorialístico parte da compreensão de que é preciso retornar à ferida colonial e reinscrevê-la no tempo, problematizar suas reverberações socioculturais. Questiona-se, nos clipes, a contemporaneidade das imagens colonialistas, exigindo-se que se supere "a tara nessa caravela" (Eminência Parda), demandando um outro lugar histórico e social.

O entrecruzamento dos tempos ocorre pela ruptura da linearidade temporal por meio da mescla verbo-visual das temporalidades - nas quais passado e presente ficam, simultaneamente, em tela, dando espessura à experiência temporal. O objetivo é mostrar a permanência e a duração estendida das violências que, sob novas roupagens, figuram de modo naturalizado na vida social. Nessa perspectiva, em Boa Esperança, há um verso renitente no refrão que diz: "E os camburão o que são?/Negreiros a retraficar/Favela ainda é senzala, Jão!/Bomba relógio prestes a estourar". A sonoridade forte transcorre enquanto surgem na tela imagens de crianças correndo nas matas com focos de incêndio no entorno da cidade e, num corte na imagem, revelam-se mulheres e homens negros uniformizados iniciando sua rotina de trabalho em uma mansão, mesclando a escravização colonial e a atual exploração dos trabalhadores.

A crítica ao passado também ocorre poeticamente ao associar-se o mar salgado - diferente de Fernando Pessoa que o vê como fruto dos lamentos dos portugueses pela partida - como "lágrima de preto", espoliado, escravizado e violentado com a retirada de sua terra, sua cultura, sua história (EMICIDA, 2018). Tal como o sabor do mar, a opacidade histórica ainda persiste e, por isso, a saída é retornar ao passado para reescrevê-lo, refundá-lo, para que ele não seja esquecido, assentando em um presente sem lastro - que o naturaliza por não vê-lo como produto de uma constituição sócio-histórica. Daí a crítica aguda e amarga ao nosso próprio tempo, "Pois na era Cyber, cêis vai ler/Os livro que roubou nosso passado igual Alzheimer" (Boa Esperança, 2015).

Esse acionamento intertextual permite uma inserção num tempo historicizado (com a presença do "Canto dos Escravos", na voz de Dona Onete, em Eminência Parda), bem como uma vinculação com o presente, ao fazer referência às críticas sofridas por Emicida ao usar um terno caro, numa premiação musical, em "meto terno por diversão/ É subalterno ou subversão?" 
(Eminência Parda). Para evidenciar o desarranjo temporal, o tensionamento entre passado/ presente, coexistem nas composições referências midiáticas (como nos versos "Tipo Mario, entrei pelo cano mas levei as princesa", numa clara referência ao jogo de videogame, em Mandume) lado a lado a remissões ao passado (ao reconhecer-se "herdeiro de Zumbi" na mesma canção).

Há um jogo imagético que evidencia as lutas constituídas no tempo, mostrando que as opressões históricas constrangem os sujeitos, mas encontram resistência nos mais diversos campos sociais, inclusive na religião. Isso aparece em Mandume, ao mostrar mulheres, em trajes rituais, sendo oprimidas em sua religiosidade pela presença de uma figura católica/cristã que Ihes impede a realização dos ritos. Logo em seguida, evidenciando a luta e oposição às opressões, uma fogueira central se expande e faz cair o homem que empunhava uma Bíblia e, a partir disso, as mulheres retomam suas práticas.

A memória coletiva também é discutida, mostrando como a ferida colonial atravessa as representações sociais dos sujeitos negros, associando-os à violência, à criminalidade, à prostituição e à morte. Esse tema ganha centralidade em Eminência Parda, no qual, num jogo de imagens, mostra-se como as pessoas brancas no entorno da família negra presente no restaurante francês conferem a eles um lugar de desumanização ao acionarem imagens racistas. No decorrer do clipe, contrapõe-se a presença da família negra que comemora conquistas e sucesso ao olhar racista e violento das pessoas ao redor - evidenciando como os clientes brancos e ricos elaboram um fluxo de pensamento opressor ao rechaçarem e desprezarem a presença da família negra em cena.

\section{b. Corporalidade desumanizada}

A corporalidade envolve a dimensão da experiência do sujeito como algo encarnado; ou seja, como uma maneira de ser que transcende a dimensão simbólica para alcançar os modos de presença na vida social. A corporalidade é passível de sofrer e suportar as condições violentas do discurso: é no corpo que se sente a dor e a violência, o abuso, o assédio e a morte. Também enquanto campo tangível, é no reconhecimento do próprio corpo - e das representações que o rodeiam e o posicionam no mundo - que os sujeitos se constituem humanos, uns em face dos outros. Por isso, a questão da corporalidade emerge pela sua capacidade de revelar a tactilidade da experiência de ser no mundo.

Nos clipes, a questão da corporalidade aparece por duas vertentes: questiona-se a baixa representatividade dos corpos negros e problematiza-se a crueza da experiência de violação corporal, decorrente da desumanização e da objetificação sofrida.

A demanda por representatividade aparece em Mandume quando, após mostrar a paisagem visual de uma banca de revistas - na qual todas as capas contêm pessoas brancas - ser coberta, 
pela intervenção de jovens negros, por imagens de Elza Soares, Thaíde e Rappin Hood, entre outros/ as, fazendo dali um espaço de inscrição dos corpos negros em posições referenciais e valorizadas.

Trata-se também da corporalidade ao se opor à sexualização dos corpos das mulheres, representando-as como lutadoras. Tais imagens são casadas ao discurso forte e ritmado de Drik Barbosa, na qual ela anuncia "Feminismo das preta bate forte, mó treta/Tanto que hoje cês vão sair com medo de bu[ceta]/Drik Barbosa, não se esqueça/ Se os outros é de tirar o chapéu, nóiz é de arrancar cabeça" (Mandume). Falar em feminismo aqui não nos parece algo aleatório, uma vez que isso assenta as bases para um discurso do empoderamento das mulheres negras e mostra o espraiamento dessas lutas - que envolvem o discurso, o corpo e a vida social. Além disso, a presença forte de Drik Barbosa já nos primeiros versos do clipe, longe de apelar para uma feminilidade fragilizada - uma representação tão recorrente na cultura midiática - revela, pelas batidas, pelo ritmo, pela gestualidade, a resistência e a força da mulher negra em tela.

Nesse mesmo clipe temos ainda todo o grupo vestindo-se com as roupas da coleção Yasuke, produzida pela Laboratório Fantasma - empresa gerenciada por Emicida e seu irmão Evandro Fióti - lançada na São Paulo Fashion Week de 2016. Ao adotar essas roupas, demarca-se o lugar da marca enquanto produção coletiva e ainda se reivindica o lugar de um próprio, acenando também para o que esse desfile representou num contexto extra-clipe: foi a primeira aparição de uma coleção desfilada somente por pessoas negras na história do evento, alcançando o que foi visto como uma luta por representatividade também nas passarelas (REZENDE, 2020).

Quanto à violência e ao controle dos corpos temos, em Boa Esperança, pela sutileza imagética das cenas - embora ferina na denúncia das relações sociais - uma representação do olhar impositivo e constrangedor da empregadora que exige o uso de uma touca para cobrir os cabelos das trabalhadoras domésticas e pelo abuso das falas assediadoras dos homens ao ouvido delas. A violência - além de sexual - se desdobra ainda na culpabilização de uma jovem negra assediada pela esposa de um dos agressores que a ataca, esfregando-Ihe violentamente o rosto para a retirada do seu batom. O tratamento do assédio sexual não se limita ao tema da violência sofrida pelas mulheres negras, pontuando a sexualização do corpo masculino, ao dizer "Cês diz que nosso pau é grande/ Espera até ver nosso ódio" (Boa Esperança). Essa fala, carregada de revolta, denuncia a objetificação e desumanização dos corpos negros, reduzidos de sua condição de ser.

Em contraposição à objetificação e à desumanização, as cenas da revolta dos trabalhadores domésticos ganham mais fôlego quando adotam simbologias coloniais para constranger os corpos brancos - ao acorrentá-los às cadeiras e amordaçá-los. Uma cena potente para denunciar as humilhações é o gozo incendiário das empregadas que atiçam fogo nas roupas brancas no varal - roupas que ali, expostas, sinalizam uma vida de trabalho assentada no silêncio submisso diante das agressões que Ihes permeavam o dia a dia e entretecia o cotidiano oprimido de suas vidas. 
Complementarmente, a violência representacional alcança mesmo relações distanciadas, como trata Eminência Parda, em que a família negra é julgada pelas pessoas brancas ao redor. No fluxo das imagens, mesclando a presença da família e a representação imaginária feita pelos brancos no entorno, figuram representações depreciadoras e violentas. Eles são vistos como pobres, criminosos, prostituídos, acorrentados - imaginariamente - a um mastro (remetendo ao "tronco") no restaurante. Ao final, é fabulada a morte coletiva da família. Torna-se manifesto o ódio sanguinário e a violência das representações sociais que lhes cercam e o desejo (des)velado de seu desaparecimento e sua subtração daquele espaço. A denúncia se fundamenta, no clipe, não só pelo desejo virulento de mantê-los em lugares sociais pré-estabelecidos por um sistema enraizado na colonialidade, quanto pelo desejo de sua morte.

Essa família não é vista nem percebida na sua presença porque desencaixa e desarranja as expectativas e projeções do grupo de pessoas ricas e brancas que lhes encara. Mesmo com todos os elementos da cena contrariando o viés racista acionado pelos demais clientes do restaurante, eles se recusam a perceber a presença da família negra por uma outra perspectiva. Isso evidencia a recusa e a resistência de se mover o olhar racista, escancarando, assim, a violência dessa percepção.

\section{c. Vida livre da violência e da morte}

Uma das ponderações cruciais da colonialidade do ser é a presença, constante, do assombro da morte precoce e violenta. Mais do que um horizonte que integra o ciclo de vida humano, ela constitui a experiência de viver no cotidiano, pois é um imperativo jamais esquecido. Essa problematização não é aleatória. Dados recentes pontuam que

\footnotetext{
apenas em 2018, para citar o exemplo mais recente, os negros (soma de pretos e pardos, segundo classificação do IBGE) representaram 75,7\% das vítimas de homicídios, com uma taxa de homicídios por 100 mil habitantes de 37,8. Comparativamente, entre os não negros (soma de brancos, amarelos e indígenas) a taxa foi de 13,9, o que significa que, para cada indivíduo não negro morto em 2018, 2,7 negros foram mortos. Da mesma forma, as mulheres negras representaram $68 \%$ do total das mulheres assassinadas no Brasil, com uma taxa de mortalidade por 100 mil habitantes de 5,2, quase o dobro quando comparada à das mulheres não negras (Atlas da violência, 2020, p. 41).
}

A reivindicação de uma vida livre da violência e da morte nos clipes explicitam um gesto de re-existência e uma denúncia da letalidade do mundo social. Há várias cenas que poderíamos pontuar em Mandume para tratar da violência e da morte; no entanto, para além de evidenciar a denúncia, o traço mais marcante do clipe é a re-existência pelo gesto estético. Desde a performance dos rappers até a atuação dos atores, há um olhar forte encarando a câmera. Nesse clipe, os olhos nos olhos assumem uma potência singular: mais do que criar um laço com quem assiste e denunciar uma consciência de sua presença, eles reivindicam o reconhecimento mútuo de um lugar de sujeito. 
O olhar cria uma ligação intersubjetiva que demanda o encontro com o outro, humaniza-o e demanda a transformação das relações opressivas vigentes. Tal gesto participa da denúncia da colonialidade do ser, na qual a morte e a violência são naturalizadas porque desumanizam o outro. Daí, é um ato de resistência encararmo-nos, olharmos nos olhos - exigir ser visto: reconhecendo-nos mutuamente como sujeitos, a morte e a violência tornam-se inaceitáveis.

Já para reivindicar uma vida digna, denunciam-se todas as marcas de indignidade espalhadas na convivência cotidiana e social. Se ao fim de Boa Esperança a jornalista informa que as empregadas domésticas amotinadas no país clamavam por dignidade, respeito e melhores condições de trabalho, a imagem da perda e da destituição da dignidade permeia todo o clipe, mostrando o desafio colocado por essa demanda. Nas cenas, uma das empregadas almoça à mesa no quintal da casa, com um prato metálico, reservado aos empregados, próxima do cachorro recebendo sua ração; em outro momento, um dos empregados recolhe as chaves do carro no chão, displicentemente "derrubadas" por um dos homens brancos e ricos, instituindo uma ordem de interação marcada pelo rebaixamento e pela humilhação. Essa desvalorização da vida, esse exercício constante de retirada da dignidade, acontece por meio de gestos que, em cenários mais amplos, mostram o quanto a vida desses grupos é privada de respeito, cuidados e dignidade, como afirmando no excerto "Aê, nessa equação chata, polícia mata, plow!/ Médico salva? Não! / Por quê? Cor de ladrão".

O gesto re-existente marca também reconhecimento da potência de intervenção social do rap. Em Eminência Parda, exige-se refundar o passado pelas rimas para, daí, fazer-se presente na própria história: "Não sou convencido(não) sou convincente /Aí, vê na rua o que as rima fizeram" (Eminência Parda) e também se afirma a coletividade desse gesto estético, ao dizer: "Minha caneta tá fodendo com a história branca/ E o mundo grita, não para, não para, não para" (Eminência Parda). A reescritura e reinscrição do próprio passado reivindica, assim, um novo lugar no tempo e uma outra forma de representação, que já não se limita mais às imagens do crime, da violência, da sexualização, da morte, exigindo uma valorização social, como dito em "A partir de agora é papo reto sem rodeio / Olha direto nos olhos de um preto sem receio / Dizem que eu cruzei a meta / Pra mim nem comecei / Cheguei, rimei, ganhei, sou rei" (Eminência Parda).

\section{CONSIDERAÇÕES FINAIS}

Ao longo dos clipes, o acionamento da ferida colonial conduz a um retorno memorialístico ao passado, indicando a necessidade de reescrever e refletir sobre a experiência sócio-histórica; 
faz-nos perceber a necessidade de questionar e criticar as organizações temporais que situam a escravização e a colonização como marcas encerradas no tempo, observando sua permanência no tecido social. O retorno memorialístico ao passado, além de revelar novas possibilidades narrativas para os eventos históricos, mostra que a colonialidade do ser - que naturaliza a destituição da subjetividade - espraia-se no sistema de representações sociais promovendo violências que ecoam nos corpos, nas relações e na vida cotidiana.

A corporalidade desumanizada pela sexualização e pela passibilidade da violência é mostrada tanto para denunciar a violência e o assédio às mulheres negras, quanto a sexualização dos corpos masculinos. Além disso, mostra-se que a negação de um lugar de valor às corporalidades negras incide na baixa representatividade e na negação da diversificação das formas de representação social. Ao problematizar a violência das relações estabelecidas, marcadas pela desumanização dos corpos, por meio de representações e discursos que constrangem, oprimem e agridem os sujeitos, evidencia-se a objetificação como um gesto naturalizado que precisa ser questionado. Também quando se denuncia a presença cotidiana da morte para a população negra, exige-se o direito à vida livre da violência e da morte.

Os clipes tensionam as representações e as formas narrativas contemporâneas e, com isso, convocam para uma transformação nas maneiras de se compreender as relações sociais. No pano de fundo dessas produções, essa transformação se constitui também pelo estabelecimento de um laço intersubjetivo (seja pelas narrativas, seja pelos olhos nos olhos que nos conectam) por meio do qual se abre caminhos para a reinvidicação de outros lugares na história e na vida social.

Tais clipes participam ainda de um movimento estético, no qual a ferida colonial aparece sob a forma de questionamento do presente e do passado, numa luta pela enunciação e fundação de outras relações sociais. É, portanto, aí que reside a grande relevância dessas obras analisadas: ao reconfigurar o passado e o presente - pontuar outras experiências históricas, valores, perspectivas sobre os modos de ser e estar no mundo social - permite-se a emergência de outras imaginações, outras possibilidades de organizar a vida social. A re-existência estética aparece, assim, como essa inventiva e necessária capacidade de reivindicar outras existências possíveis.

\section{REFERÊNCIAS}

ALBÁN ACHINTE, Adolfo. Estéticas de la re-existencia: ¿Lo político del arte? In: MIGNOLO, Walter; GÓMEZ, Pedro Pablo. (orgs.). Estéticas y opción decolonial. Bogotá: Universidad Distrital Francisco José de Caldas, 2012, p. 281-295. 
ATLAS DA VIOLÊNCIA - 2020. Instituto de Pesquisa Econômica Aplicada: Brasília, 2020.

BHABHA, Homi K. O local da cultura. Belo Horizonte: UFMG, 1998.

CAMARGOS, Roberto. Rap e Politica: percepções da vida social brasileira. São Paulo: Boitempo, 2015.

EVARISTO, Conceição. Da grafia-desenho de minha mãe um dos lugares de nascimento de minha escrita. XI Seminário Nacional Mulher e Literatura - II Seminário Internacional Mulher e Literatura, Rio de Janeiro, 2005. Disponivel em: http://nossaescrevivencia.blogspot.com/2012/08/da-grafia-desenho-de-minha-mae-um-dos.html

Decodificando Emicida - Boa Esperança, pt.1. Produção de Emicida. São Paulo: Laboratório Fantasma, 2018. 12’59’". Disponível em: https://www.youtube.com/watch?v=qi5W4m2k_6w. Acesso em 23/10/2020.

LUGONES, María. Rumo ao feminismo descolonial. Estudos Feministas, Florianópolis, v. 22, n. 3, p. 935- 952, set.-dez./2014. MALDONADO-TORRES, Nelson. Sobre la colonialidad del ser: contribuciones al desarrollo de un concepto. In: CASTRO-GÓMEZ, Santiago; GROSFOGUEL, Ramón. (orgs.). El giro decolonial: reflexiones para una diversidad epistémica más allá del capitalismo global. Bogotá: Siglo del Hombre Editores; Universidad Central, Instituto de Estudios Sociales Contemporáneos y Pontificia Universidad Javeriana, Instituto Pensar, 2007, p. 127-167.

MIGNOLO, Walter. El pensamiento decolonial: desprendimiento y apertura - un manifiesto. In: CASTROGÓMEZ, Santiago; GROSFOGUEL, Ramón. (orgs.). El giro decolonial: reflexiones para una diversidad epistémica más allá del capitalismo global. Bogotá: Siglo del Hombre Editores; Universidad Central, Instituto de Estudios Sociales Contemporáneos y Pontificia Universidad Javeriana, Instituto Pensar, 2007, p. 25-46.

MIGNOLO, Walter. La ideia de America Latina: la herida colonial y la opción decolonial. Barcelona: Gedisa, 2005.

PRADO, Denise. O Triunfo de Emicida - um rap em dois momentos. In: FRANÇA, Vera; SIMÕES, Paula; PRADO, Denise. Celebridades do século XXI - diversos perfis, diferentes apelos. Vol. 2. Belo Horizonte: Selo PPGCom, 2020, p. 229-247.

QUIJANO, Aníbal. Dom Quixote e os moinhos de vento na América Latina. Estudos Avançados, São Paulo, n. 55, v. 19, p. 9-31, 2005.

REZENDE, Karla B. C. de P. Combatendo os estereótipos e o racismo nos desfiles da Laboratório Fantasma. In: PRADO, Denise F. B.; TAVARES, Frederico de M. B.; TAVARES, Michele S. Mídia, tempo e interações sociais: conceitos em circulação. Belo Horizonte: PPGCom, 2020, no prelo.

SOARES, Thiago. A estética do videoclipe. João Pessoa: Ed. UFPB, 2013.

TATE, Shirley. Descolonizando a raiva: uma teoria feminista negra e a prática nas universidades do Reino Unido. In: BERNARDINO-COSTA, Joaze. MALDONADO-TORRES, Nelson. GROSFOGUEL, Ramón. (orgs.) Decolonialidade e pensamento afrodiaspórico. Belo Horizonte: Autêntica Editora, 2019, p.183-202. 
TEPERMAN, Ricardo. Se liga no som: as transformações do rap no Brasil. São Paulo: Claro enigma, 2015.

TLOSTANOVA, Madina. La aesthesis trans-moderna en la zona fronteriza eurásica y el anti-sublime decolonial. In: GOMEZ, Pedro Pablo [et al]. (orgs.) Arte y estética en la encrucijada descolonial II. Ciudad Autónoma de Buenos Aires: Del Signo, 2014. (p. 79-108)

[1] O clipe Boa Esperança, com música de Emicida e Nave, dirigido por Kátia Lund e João Wainer, foi lançado em 2015. Sua produção é da Laboratório Fantasma. Esse rap integra o álbum “Sobre Crianças, Quadris, Pesadelos e Lições de Casa” (2015).

[2] O clipe Mandume, de Emicida, foi lançado em 2016 e conta com a participação de Drik Barbosa, Amiri, Rico Dalasam, Muzzike e Raphão Alaafin. Esse rap faz parte do álbum "Sobre Crianças, Quadris, Pesadelos e Lições de Casa” (2015).

[3] Eminência Parda, de Emicida, foi lançado em 2019, pela Laboratório Fantasma, e conta com a participação de Dona Onete, Jé Santiago e Papillon, e faz parte do álbum “Amarelo" (2019).

[4] “As explosões provenientes da consciência teórica, política e ética da ferida colonial despertam a imaginação e permitem a construção de outro mundo, um mundo no qual muitos mundos são possíveis” (MIGNOLO, 2005, p. 175-176, tradução nossa).

[5] Conforme explica Lugones, “eu compreendo a hierarquia dicotômica entre humano e o não humano como a dicotomia central da modernidade colonial. (...) A missão civilizatória, incluindo a conversão ao cristianismo, estava presente na concepção ideológica de conquista e colonização. Julgar os/as colonizados/as por suas deficiências do ponto de vista da missão civilizatória justificava enormes crueldades” (LUGONES, 2014, p. 936-937).

[6] "A antecipação da morte não é tanto um fator individualizador, como uma característica constitutiva de sua realidade" (MALDONADO-TORRES, 2007, p. 143, tradução nossa).

[7] Essa relação perversa estabelecida nas bases da colonialidade do ser é tratada por Maldonado-Torres ao explicar que, "en cuanto toca a la concepción de sujetos, el racismo moderno y por extensión la colonialidad, puede entenderse como la radicalización y naturalización de la no-ética de la guerra. Esta no-ética incluyó prácticas de eliminación y esclavización de ciertos sujetos particularmente, pero no únicamente, indígenas y negros - como parte de la empresa de la colonización. La expresión hiperbólica de la colonialidade incluye el genocidio, el cual representa el paroxismo mismo del ego conquiro/cogito - un mundo en el que éste existe solo" (MALDONADO-TORRES, 2007, p. 138, grifos do autor) ("no que se refere à concepção de sujeito, o racismo moderno e, por extensão, a colonialidade, pode ser entendido como a radicalização e naturalização da "nãoética" da guerra. Essa 'não-ética' incluía práticas de eliminação e escravização de certos sujeitos - particularmente, mas não exclusivamente, indígenas e negros - como parte do empreendimento de colonização. A expressão hiperbólica da 
colonialidade inclui o genocídio, que representa o próprio paroxismo do ego conquiro/cogito - um mundo no qual ele existe sozinho" (tradução nossa)).

[8] Esse autor problematiza o lugar do grito/pranto na constituição do pensamento afrodiaspórico. Para ele, a pergunta existencial fundante desse pensamento - "Por que continuar", feita por Gordon Lewis - contribuiu para iluminar a dimensão existencial dessa linha de pensamento. Assim, o grito/prato se constituem como uma chamada à atenção que anima o surgimento dessa corrente de pensamento e a busca pela constituição do lugar sócio-histórico dos condenados/ damnès (no sentido colocado por Fanon).

[9] "O que é invisivel sobre as pessoas de cor é sua propria humanidade. E é sobre a essa negação [da própria humanidade] que o grito e o pranto tentam chamar a atenção. A invisibilidade e a desumanização são as expressões primárias da colonialidade do ser” (MALDONADO-TORRES, 2007, p. 150, tradução nossa).

[10] Na já famosa citação da escritora, "A nossa escrevivência não pode ser lida como histórias para 'ninar os da casa grande' e sim para incomodá-los em seus sonos injustos” (EVARISTO, 2007).

[11] "Trata-se de curar uma mente e uma alma colonizadoras, libertando a pessoa de complexos coloniais de inferioridade, e permitindo que ela sinta que também é um ser humano com dignidade, que também é valiosa como é” (TLOSTANOVA, 2014, p. 88, tradução nossa).

[12] "Certamente, o que chamo de estéticas da re-existência nada mais é do que o ato político de viver procurando, sem qualquer negociação, alcançar a dignidade e desestruturar as formas de poder e dominação que, do material ao simbólico, se constituem e circulam nesta época de um capitalismo desenfreado e criminoso. Talvez as estéticas de re-existência sejam o sussurro das práticas decoloniais que vislumbram outras formas de bem viver” (ALBÁN ACHINTE, 2012, p. 293, tradução nossa). 